\title{
Aspect in ASL: A Typological-Functional Analysis
}

\author{
ELISA M. MARONEY \\ University of New Mexico
}

\section{Introduction}

This research reports on patterns of aspect in American Sign Language (ASL). Typological research already done on aspect in spoken languages provides a framework from which the aspectual system in ASL is investigated. The findings of this study show that aspect in ASL has formal, semantic, and functional properties comparable to other languages of the world and that the majority of the aspectual categories already identified in ASL are expressed lexically and derivationally rather than inflectionally as previously reported (Fischer 1973, Fischer and Gough 1978, Klima and Bellugi 1979, Anderson 1982, Liddell 1984, 1990, Sandler 1990, Brentari 1996, 1998, Sutton-Spence and Woll 1999). The aspectual senses reported on here include progressive, continuative, habitual, frequentative, iterative, anterior (or perfect), completive, resultative, and inceptive. These findings have implications for all of the research that has been done on morphology in ASL. Broad statements saying that morphological categories in ASL are inflectional need to be re-examined.

\section{Language consultants}

The five language consultants who participated in this research are Deaf, native ASL signers. Initially, data was gathered from four language consultants. Each one of the four is a native ASL signer who began acquiring ASL as an infant. Each considers ASL her/his first language. At the time that data was collected, the language consultants were between the ages of 27 and 42. Each of the language consultants has either taught or currently teaches ASL at the postsecondary level. All are from the western United States (Oregon, Idaho, Montana, and Colorado). Each of the four language consultants holds a Master's degree in Deaf Education or a very closely related field. Of these four language consultants, two were female and two male. The fifth language consultant was identified to provide native insights for the researcher during the analysis stage of the investigation. This consultant was a female, native signer, age 29. She was an undergraduate student majoring in linguistics, involved in linguistic research, as subject, consultant, and/or research assistant. She has taught ASL at the postsecondary level. 
When discussing the data, there were times when specifying the language consultant was important. They are simply "the first language consultant", "the second language consultant", "the third language consultant", "the fourth language consultant", and "the fifth language consultant". The first and fourth language consultants are male and the second, third, and fifth are female.

\section{Methodology}

The procedures for this research included two narratives and a written questionnaire adapted from Dahl (1985). Language consultants were videotaped during each procedure. The narrative elicitation consisted of two parts. In the first part, language consultants were asked to view a wordless action story on videotape, titled "The Pear Story", after which they were asked to narrate the story in ASL (See Chafe 1980, for other studies using "The Pear Story"). In the second part, language consultants were asked to narrate in ASL a picture story, titled "Frog, where are you?" (Mayer 1969). Language consultants were asked to look through the story in its entirety and then to sign the story while viewing the pictures a second time (See Berman and Slobin 1994 for other studies using "Frog, where are you?").

The sentences adapted from Dahl's (1985) questionnaire were translated from written English to ASL by the ASL consultants. The translation process influences results of the Dahl (1985) survey. However, if there were obligatory markings for any or all of the aspectual categories, they would have occurred. Translation was used to develop a typologically oriented database from which to compare and contrast the aspectual systems of several different languages.

The questionnaire adapted from Dahl (1985), was comprised of twenty-five sentences and three connected texts (short paragraphs consisting of two to five sentences each). The aspectual categories and their prototype sentences reported by Dahl (1985) were isolated ${ }^{1}$ and included in the questionnaire for this project. The results from the progressive, habitual, and perfect (or anterior) sentence types will be reported here. The Dahl questionnaire does not elicit iterative, continuative, frequentative, completive, resultative, or inceptive, because they are not prototypically found in languages to be inflectional categories.

Transcription conventions that will be used in this paper are:

1. ALL CAPS represents the English gloss for the sign used.

2. Hyphen (-) indicates that more than a one-word English gloss is necessary.

3. A plus sign $(+)$ is used to indicate total or partial reduplication.

4. A number sign (\#) represents a fingerspelled loan sign.

5. PRO.1, PRO.2, PRO. 3 indicates $1 \mathrm{~s}, 2 \mathrm{~s}$, and $3 \mathrm{~s}$, respectively.

6. Specific labels are used for the two forms of FINISH following Janzen (1998): Main verb: BE.FINISHED and Anterior: FINISH.AUX ${ }_{(\text {ant })}$

\footnotetext{
${ }^{1}$ The Dahl (1985) questionnaire is comprised of 165 items to elicit information on tense and aspect. For this survey, only the items used to elicit information on aspectual categories were used.
} 


\section{Elisa M. Maroney}

\section{Expression of imperfective aspectual senses in ASL}

In this section, the focus is on the aspectual meanings that relate to ongoing, repeated, or present situations. Expressions of the imperfective, progressive, and frequentative will be touched upon briefly, because no evidence of markers for these categories were found in the data for this study. The related aspectual meanings that will be described in more depth are iterative, habitual, and continuative.

For the purposes of this research, inflectional, derivational, and lexical expression are best understood when placed on a continuum of expression types. Inflectional morphology has a high degree of productivity and obligatoriness, while derivational morphology is characterized by a low degree of productivity and lack of obligatoriness. Both inflectional and derivational expressions are characterized by boundedness. Lexical expression is highly fused. In other words, lexical expression is characterized by the expression of both meaning and form with one morpheme. Some categories of aspect are more commonly expressed inflectionally, while others are more commonly expressed derivationally. The aspectual meanings that are expressed in ASL derivationally and/or lexically will be described. Imperfective and progressive, both commonly found as inflectional categories in the languages in which they occur will be discussed briefly here to establish the difference between inflectional and derivational aspectual categories.

Comrie (1976) writes that meaning is considered imperfective when an event is viewed from the inside and can be separated into parts or the internal structure of the event may be distinguished, such as the beginning or ending. An imperfective event may also be seen as ongoing without a beginning or an end. When an event is viewed imperfectively, it is viewed as a series of phases from inside the event. In the ASL data for this research, an obligatory, productive marker for an inflectional category of imperfective meaning was not found.

\subsection{Repeated Situations}

Signed languages are unique in their ability to express meanings with a high degree of iconic representation. The data for this research provides many examples of the iconic relationships between aspectual expression and the real-world event that it represents. Bybee (1985) writes that "reduplication is more common among derivational processes than among inflectional". Bybee et al. (1994) predict that the earlier, more complete forms of a reduplicated stem are maximally iconic in that the repetition of the verb signals repetition of the action described by the verb. In their sample, they found that the meanings most commonly expressed with total reduplication are the closely related senses of iterative, frequentative, and continuative. They believe that evidence is strong indicating that iterative is the original meaning associated with full reduplication. They found that the differences between iterative and continuative have to do with the types of verbs with which they may occur. The iterative applies best to punctual or telic verbs while the continuative best applies to both telic and atelic predicates. The iterative may generalize to continuative by expanding to atelic verbs. 


\section{Aspect in ASL: A Typological-Functional Analysis}

Frequentative implies occurrence on different occasions, again seeming to generalize from iterative meaning that occurs on one occasion. No examples of frequentative were found in this data. Habitual and progressive are more general still, and Bybee et al. (1994) suggest that habitual develops from frequentative while progressive develops from continuative.

Since the meanings of iterative, frequentative, and continuative tend to be closely related to the stem that is reduplicated, these meanings are more likely to be expressed as derivational morphology. Further, semantic restrictions (i.e., the uses of each aspectual meaning with specific verb types) are more characteristic of derivational morphology. As will be seen below, the semantic specificity and semantic restrictions characteristic of derivational morphology appear in the aspectual expression in ASL.

Iterative expresses the repetition of an event occurring during a single occasion and is particularly relevant to telic verb forms. The iterative refers to a situation that is repeated (e.g., 'a series of coughs') on a particular occasion and may also carry continuative meaning, as in to 'keep on doing'. In this data set, iterative was used with telic verb forms, the vast majority of which were activities with one example of a semelfactive verb. Both activities and semelfactives are telic verb types. Several examples of iterative appear in the two narratives procedures used in this research, "The Frog Stories" and "The Pear Stories". Reduplication was the only way that the iterative meaning was expressed in the narrative data for this research.

The reduplicated forms of the verbs with iterative meaning fit more appropriately into a derivational process than an inflectional one. Rather than having a constant, obligatory, and productive phonological shape, each reduplicated stem has a different movement allomorph with which the reduplication occurs. The iterative tends to be produced with a straight movement and then an arc movement down and back. However, this movement varied depending on the sign. For example, when language consultants signed picking pears, the movement was more circular. When they signed LICK, the repetition that expressed iterative was the repetition of the index and middle finger. The movements of the entire hand expressed distributive meaning (i.e., while the index and middle finger were repeating the movement meaning 'lick', the hand was moving to various places on the arm or chest indicating that those areas were being licked).

In this data, the total number of repetitions for both adjacent and non-adjacent reduplicated forms ranged from 1-19. The reduplicated forms that were adjacent had repetitions that ranged from 1-6. In every example of iterative aspectual expression on a verb that was reduplicated more than once by an individual signer or among more than one signer, the number of repetitions is unpredictable, a characteristic of derivational morphology. Although idiosyncrasies and unpredictable forms are often considered characteristic of grammaticization, the reduplication used to express iterative meaning in ASL only occurred on activity verbs.

\footnotetext{
${ }^{2}$ The narratives require use of the iterative and continuative, but not habitual and frequentative.
} 


\section{Elisa M. Maroney}

This semantic restriction is indicative of non-inflectional morphology. The meanings of the forms used to express iterative are close to the original source meanings, representing repetition of the original event, and the meanings have not generalized semantically. Instead, the meanings are quite specific with the repetition of the original source simply indicating that the action being represented is repeated on that occasion.

The meaning of habitual is that a situation is characteristic of a period of time. Narrative discourse usually refers to an event that occurred before reference time and within a well-defined temporal frame. Habitual was not readily elicited with the two narrative texts. No examples of habitual occurred in the two narrative discourse sets. However, examples of habitual meaning did arise in the Dahl (1985) questionnaire.

In every instance of habitual, an aspectual verb (e.g., TEND) and/or a noun (e.g., HABIT) and/or an adverbial sign (e.g., NOW-AND-THEN) were used. In the questionnaire data, the most consistent item that occurred in habitual contexts was the verb, TEND. This data indicates that if a language consultant chooses to use reduplication, then another form (e.g., a verb or a noun) must be used to express habitual meaning. ASL users have options in how to express habitual meaning. There is no obligatory, grammaticized form of habitual in ASL. If reduplication is used when habitual is the intended meaning, something in addition to the reduplicated form of the verb must occur to distinguish habitual meaning from iterative or continuative. The verbs that were reduplicated had 1-6 repetitions and the number of repetitions is not predictable.

\subsection{Ongoing situations}

The continuative expresses that a dynamic situation is ongoing and that the agent of the action is deliberately keeping the action ongoing. The progressive is more generalized than continuative and occurs more frequently as inflectional morphology in the languages in which it occurs. No progressive marker was found in the data for this study. If there were an obligatory progressive marker in ASL, it would have shown up in the data when the progressive was being elicited.

The examples of continuative are from the two narratives. Like other aspectual expression in ASL, signers have options for how to express the continuative meaning. Continuative expression in the ASL data for this research included reduplicated forms, lexical items, a nonmanual marker, and the representation of two events co-occurring on two separate articulators.

When reduplication was used to express the continuative, some other marker was used to distinguish it from iterative. With continuative meaning, the movement was sometimes circular, while the iterative was sometimes produced with a straight movement and then an arc movement down and back. When the continuative is produced with the arc movement, it may be distinguished from iterative by using a nonmanual marker that is formed by putting the mouth in an ' $m$ m' position. When this nonmanual marker was used, the continuative could be differentiated from iterative meaning. A third way that continuative meaning 


\section{Aspect in ASL: A Typological-Functional Analysis}

could be distinguished from iterative was by the use of a lexical item, such as MORE or CONTINUE.

Berman and Slobin (1994) note that simultaneity can signal that two events are ongoing or co-occurring. Signed languages are unique in that different things may be expressed simultaneously on different hands. Thus, another way to express that two activities are co-occurring is by signing two activities happening on separate hands at the same time. For example, when the boy was bicycling away from the tree and then a girl started bicycling toward him, all of the language consultants represented a vehicle classifier, CL: $3_{\text {vehicle, on separate }}$ hands, the vehicles coming toward each other, in front of the signer, and then passing each other at the midpoint. This represents two events co-occurring simultaneously. The second language consultant signed the following example:

$\mathrm{mm}$

LOOK-AT (1-hand to 2-hands)+++++ 'hands-on-chin.'

[frog in jar] [dog and boy]

'The boy and his dog are watching the frog for awhile.'

This is an interesting example, because several means for expressing continuative meaning were utilized within the same construction. First, the language consultant used two articulators simultaneously to represent the boy and the dog continuing to look at the frog. Second, the sign LOOK-AT was reduplicated with iterative movement accompanied by the nonmanual signal, 'mm'. Finally, she put her hands on her chin to show that the boy was still watching the frog. This is the unique feature of iconicity in ASL that affords the signer an opportunity to act out the action portrayed in the stories they tell. These constructions express continuative meaning; while one event is taking place, another event is happening simultaneously.

\section{Perfective, anterior/perfect, and related senses}

Perfective senses are used to represent the situation as bounded, often emphasizing the beginning or ending of an event. In the data for this study, completive, anterior, resultative, and inceptive meanings were expressed. Perfective is used for narrating sequences of discrete events, so, if there were an obligatory perfective marker, the narrative data for this research should have elicited it. In the narrative data, there were no examples of the perfective form. Further, four items in the Dahl (1985) questionnaire were used to elicit perfective meaning and no examples of perfective forms were expressed in response to these items.

Bybee et al. (1994:57) write that the completive means 'to do something thoroughly and to completion' (e.g., 'to eat up' and 'to shoot someone dead'). Completives tend to have other uses, as well. First, the object of the action may be totally affected, consumed, or destroyed by the action (as in 'eat up'). Second, the action may involve a plural subject of intransitive verbs or objects of transitive verbs, especially exhaustive or universal plural, such as 'everyone died' or 'he 
took all the stones'. Third, the action may be reported with some emphasis or surprise value. The emphatic value was especially mentioned in connection with the use of a completive in imperative sentence types. There is also a certain emphasis inherent in the notion of having brought an action to a thorough conclusion.

Completives differ from resultatives in that the completives all come from dynamic verbs or directionals, all suggesting action or movement. Resultatives, on the other hand, derive from stative verbs. The mode of expression for completives tends to be periphrastic and derivational. They tend to be rich in lexical meaning and have lexical restrictions, or they are not used frequently enough to have become inflectional. Those completives that are believed to have 'finish' as the lexical source, may develop into anteriors.

In the data for this research, the completive meaning was primarily expressed through the use of verb types that have the inherent lexical meaning of completion. The examples were accomplishment verbs that are telic in nature and are comprised of a process and a change of state. The lexicalized signs that were found with the inherent sense of completion were in the narratives.

In the Frog Stories, the signs DISAPPEAR, VANISH, and ESCAPE have inherent completive meaning. All of these verbs are accomplishment verb types. Each begins with some entity present and ends with the disappearance of the entity. In example (2) below, from the Frog Stories, the boy and the dog have awakened to find that the frog, who was there in the jar the night before, has completely disappeared. This sentence was expressed with surprise. As mentioned above, Bybee et al. (1994) found that the completive tends to have meanings attached to it, such as the action being reported with some emphasis or surprise. In example (2), VANISH has been used in just this way.

\section{BOY, \#DOG WAKE-UP LOOK (at jar) VANISH (2 handed)!}

'The boy and the dog wake up and look at the jar; the frog has vanished!'

In the Pear Stories, GONE was used by three of the language consultants. It appeared in sentence-final position each time it was used. The third and fourth language consultants used the sign GONE when describing how the boy got back up on his bicycle after stopping and picking up the basket of pears, then rode off and disappeared. The third language consultant used GONE again when the boy is hobbling away after he fell off of his bicycle. The first language consultant used GONE at the very end of the story, the very last sign in his narrative, when the three people walked out of the scene and were gone, as in example (3):

CL: 3 ("three people walking away") GONE.

'The three people walked away and were gone.'

BE.FINISHED was used as a main verb six times in the narrative data to express completive meaning. The second language consultant used this verb to 
conclude an episode in the Pear Story and the fourth language consultant used this verb in the same way once in the Frog Story. The third and fourth language consultants used BE.FINISHED at the end of the Pear Story. The fourth language consultant stopped, looked directly at the camera and signed "FINISH". This was a complete clause meaning that the narrative had ended; perhaps, something like 'The End'. The first and fourth language consultants used BE.FINISHED at the end of the Frog Story. The first language consultant signed, "FINISH. (Pause) BOY HAPPY. GO HOME". The fourth language consultant signed a number of things that indicated that the story had ended, as can be seen in (4) below:

\section{FINISH. T-H-E E-N-D. LINES-MOVE-UP-SCREEN. CURTAIN-CLOSE. LIGHTS-OFF.}

'Finished. The end. The credits move up the screen. The curtains close. The house lights go dark.'

FINISH in this context, means that the story is completely done.

The definition of anterior is 'a past action with current relevance'. The goal of the utterance is not to locate a situation at some definite point in the past, but only to offer it as relevant to the current situation.

Bybee et al. (1994:62) write that anterior (what Dahl refers to as 'perfect') is frequent in conversational discourse. They also report that Givón found that anterior is expressed in narrative discourse where it is used for events that are out of sequence, that is, events that occurred earlier but are relevant to the events located in the discourse "now". The language consultants for this research did not express this meaning in the two stories they narrated. However, in the Pear Stories, the second language consultant did use FINISH pre-verbally once. The sign had the sense of completion and the current relevance is clear from the context, as can be seen in example (5) below:

\section{PUT ("in apron") ++++++++ (alternating hands). FINISH FILL. \\ CLIMB-DOWN L-A-D-D-E-R INDEX-down.}

'He put [lots of pears] in his apron. When he finished filling his apron pocket [with pears], he climbed down the ladder.'

Janzen (1995) explains that when FINISH is used to express anterior meaning, it is auxiliary to the verb directly following it, rather than acting as a main verb. He labels FINISH with anterior meaning as FINISH.AUX (ant). He writes that FINISH.AUX $_{\text {(ant) }}$ has become semantically more general, no longer meaning 'to complete something', and has the added sense of current relevance. FINISH with the anterior reading is produced with a single movement, rather than the holdmovement-hold of FINISH in the main verb form. The synchronic data for this research provides some support for Janzen's (1995) claim that FINISH is grammaticizing along the same path that other anteriors with similar sources in spoken languages are grammaticizing. 


\section{Elisa M. Maroney}

There are several examples of anterior meaning and form in the responses to the Dahl (1985) questionnaire. Due to the nature of these questionnaire items, most of the responses were short constructions with little context. Definitively determining whether the meanings expressed in the responses to these items are anterior and not completive or perfective is difficult and requires further research. When FINISH.AUX (ant) was used to transcribe the form used by the language consultants, the form closely resembled the characteristics Janzen (1995) attributed to the auxiliary in his study, including occurrence before the main verb, semantic generalization, and current relevance.

In response to the Dahl (1985) questionnaire, there were 28 opportunities for the anterior form of FINISH described by Janzen (1995) to occur. FINISH.AUX (ant) was used 18 times before the main verb in the sentence and consisted of a movement rather than the hold-movement-hold of the main verb, FINISH. If FINISH.AUX $_{(\text {ant) }}$ had grammaticized and become inflectional in ASL, it should have occurred every time the anterior meaning was elicited. The fact that it did occur so frequently does support the premise that grammaticization is taking place.

Bybee et al. (1994) write that the resultative denotes a state that was brought about by some action in the past and persists at reference time (i.e. 'He is gone' or 'The door is closed'). Resultatives differ from anteriors in that the resultative indicates that a state persists at reference time, while an anterior indicates that a past action is relevant to the time of speech. Like passive constructions, resultative constructions are usually comprised of the patient as the subject of the clause, with no agent present. Unlike passive constructions, a resultative is only compatible with a predicate that indicates a change of state. Resultatives are used with telic verbs that have an inherent endpoint. Several examples of resultative meaning occurred in the narrative data. The verb that was used to express resultative meaning was MISSING.

In the Pear Stories, MISSING was used by the first and third language consultants to express resultative meaning in regard to a basket of pears being gone, as in example (6), which comes from the third language consultant:

\footnotetext{
MAN PICK++++ CLIMB-DOWN-LADDER. REACHES -INTOAPRON-POCKET. CONFUSED. PRO.3 (left) PRO.3 (center) MISSING. ONE B-A-S-K-E-T MISSING. (mouths 'gone')

'The man picking pears climbs down the ladder. He reaches into his apron to begin putting them into a basket, when he notices that something is wrong. He counts his baskets and finds that one is missing. One basket is gone.'
}

In this example, the third language consultant expresses the meaning that something happened before the time of reference and is still in effect at reference time. The basket of pears is gone. Furthermore, as Bybee et al. (1994:54) write, the patient is the subject of the clause and there is no agent present. The meaning of 
the sign, MISSING, includes the idea of a change of state: something was there, but now it is gone.

The cross-linguistic definition of inceptive provided by Bybee et al. (1994: 318 ) is that 'the action or event begins'. The only example of inceptive expression in the data for this research was in the Pear Stories. The Dahl (1985) questionnaire does not elicit inceptive meaning. In the Pear Story example, the boy began to pick up a single pear, but then stopped himself and picked up an entire basket. The third language consultant produced the following example.

\section{CL:1 ('boy standing') LOOK-UP-LOOK DOWN REACH-FOR headshake ('boy begins to grab one pear, but stops') REACH-FOR (2-handed) PICK-UP (2-handed) WHOLE B-A-S-K-E-T PICK-UP (2-handed).}

'The boy looks up at the man, then down at the pears, begins to grab a single pear, but quickly changes his mind and picks up the entire basket.'

In the production of the sign REACH-FOR, the third language consultant produced the sign with the original features of the citation form and a straight movement. She subtly dropped her jaw and shook her head while holding the sign REACH-FOR, immediately followed by reaching with both hands to pick-up the whole basket of pears.

\section{Conclusion}

Researchers have long been claiming that ASL's categories of aspect, agreement, and classification are inflectional. A thorough investigation of ASL aspect was needed and, because of its relevance to the verb, was a logical means of addressing the questions regarding inflectional and derivational morphology.

There is no evidence that aspectual categories in ASL are inflectional. There are no obligatory markers to express aspectual meaning and productivity is restricted to specific verb types (e.g., iterative reduplication only occurs with telic verbs). ASL users have a number of derivational and lexical options in the expression of aspectual meaning, including aspectual verbs and nouns, adverbial signs and phrases, verb reduplication, movement modifications, non-manual markers, and combinations of the above.

Bybee (1985) writes that aspect is the most relevant meaning category to the verb, followed by tense, mood, and person/number agreement. Person/number agreement has the least influence on the verb, and is therefore the least relevant to the verb. This implies that if a language has person/number agreement on the verb, then the language would also have tense or mood and aspect marked inflectionally on the verb. I have shown that ASL does not have an inflectional category of aspect. Thus, it is unlikely that it would have inflectional categories of agreement, mood, and tense.

Attempts have been made to fit linguistic phenomena that we are finding in ASL, such as aspect and agreement, into discrete categories of derivational or 


\section{Elisa M. Maroney}

inflectional morphology without fully understanding what it means to be derivational or inflectional. Liddell (2003:52) argues that directing verbs in space has nothing to do with agreement and is not inflectional. He writes that if he is correct, then the strongest candidate for an inflectional process is not inflectional. He asks if there are any true inflectional processes in ASL grammar. This question needs to be investigated further. Other morphological categories in ASL, especially verbal categories (e.g., aspect and agreement), that have been identified as inflectional are likely expressed lexically and derivationally. The morphological categories identified as inflectional categories thus far in ASL need to be reevaluated in light of the typological-functional research done on similar categories in the world's languages.

\section{References}

Anderson, Lloyd B. 1982. Universals of aspect and parts of speech: Parallels between signed and spoken languages. In P.J. Hopper (ed.) Tense-Aspect: Between Semantics and Pragmatics. Amsterdam: John Benjamins.

Baker, Charlotte and Dennis Cokely. 1980. American Sign Language: A Teacher's Resource Text on Grammar and Culture. Silver Spring: T.J. Publishers, Inc.

Berman, Ruth A. and Dan I. Slobin. 1994. Relating Events in Narrative: A Crosslinguistic Developmental Study. Hillsdale: Lawrence Erlbaum Associates.

Brentari, Diane. 1996. Trilled movement: Phonetic realization and formal representation. In van der Hulst (ed.) Sign Linguistics: Phonetics, Phonology and Morpho-syntax. Amsterdam: Elsevier.

Brentari, Diane. 1998. A Prosodic Model of Sign Language Phonology. Cambridge: The MIT Press.

Bybee, Joan. 1985. Morphology. Philadelphia: John Benjamins.

Bybee, Joan L. and O. Dahl. 1989. The creation of tense and aspect systems in the languages of the world. Studies in language 13(1): 51-103.

Bybee, Joan L., Revere Perkins, and William Pagliuca. 1994. The Evolution of Grammar: Tense, Aspect and Modality in the Languages of the World. Chicago: University of Chicago Press.

Chafe, Wallace. (ed.) 1980. The Pear Stories: Cognitive, Cultural, and Linguistic Aspects of Narrative Production. Norwood: Ablex Publishing Corporation.

Comrie, Bernard. 1976. Aspect: An Introduction to the Study of Verbal Aspect and Related Problems. Cambridge: Cambridge University Press.

Dahl, Osten. 1985. Tense and Aspect Systems. Great Britain: Basil Blackwell.

Fischer, Susan. 1973. Two processes of reduplication in ASL. Foundations of Language 9: 460-480.

Fischer, Susan. and B. Gough. 1978. Verbs in American Sign Language. Sign Language Studies 18: 17-48.

Janzen, Terrance D. 1995. The polygrammaticization of FINNISH in ASL. Ms., University of Manitoba. 
Janzen, Terrance D. 1998. Topicality in ASL: Information ordering, constituent structure, and the function of topic marking. Doctoral dissertation, University of New Mexico.

Klima, Edward S. and Bellugi, Ursula. 1979. The Signs of Language. Cambridge, MA: Harvard University Press.

Liddell, Scott K. 1984. Unrealized-inceptive aspect in American Sign Language: Feature insertion in syllabic frames. In Joseph Drogo, Veena Mishra, and David Testen (eds.) Proceedings of the 20th Annual Meeting of the Chicago Linguistic Society, 257-270. Chicago: Chicago Linguistic Society.

Liddell, S.K. 1990. Four functions of a locus: Reexamining the structure of space in ASL. In C. Lucas (ed.) Sign Language Research: Theoretical Issues. Washington, DC: Gallaudet University Press.

Liddell, S.K. 2003. Grammar, Gesture, and Meaning in American Sign Language. Cambridge: Cambridge University Press.

Mayer, Mercer. 1969. Frog, Where Are You? New York: Dial Press.

Sandler, Wendy. 1990. Temporal aspect and ASL phonology. In S. Fischer and L. Siple (eds.) Theoretical Issues in Sign Language Research. Chicago: University of Chicago Press.

Sutton-Spence, Rachel, and Bencie Woll. 1999. The Linguistics of British Sign Language. Cambridge: Cambridge University Press.

Elisa M. Maroney

ASL/English Interpretation Program

Regional Resource Center on Deafness

Western Oregon University

Monmouth, OR 97361

503-838-8735

maronee@wou.edu 